Darko R. Radenković

Teaching Assistant University of Belgrade Faculty of Mechanical Engineering

Snežana S. Milićev

Assistant Professo University of Belgrade Faculty of Mechanical Engineering

Nevena D. Stevanović

Associate Professor University of Belgrade Faculty of Mechanical Engineering

\section{Rarefied Gas Flow in Microtubes at Low Reynolds Numbers}

Low Reynolds number, axisymmetric, isothermal, compressible, slip gas flow in microtubes is investigated in this paper. The problem is solved by the continuum equations, continuity and Navier-Stokes, along with Maxwell first order boundary condition. The analytical results are obtained by perturbation method. The solutions show a good agreement with experimental results.

Keywords: microtube, slip gas flow, rarefaction, Knudsen number, perturbation expansion

\section{INTRODUCTION}

Micro-electro-mechanical systems (MEMS), with dimensions ranging from $1 \mathrm{~mm}$ to $1 \mu \mathrm{m}$ have found many applications in engineering and scientific researches [1]. MEMS are often operated in gaseous environments, where the ratio of the molecular mean free path to characteristic dimension is not negligible. Hence, the rarefaction phenomena often exist in MEMS.

The Knudsen number $K n$ is used to identify rarefaction effects. This number represents the ratio of the mean free path to the characteristic length in flow field. The following four regimes are defined based on the value of Knudsen number [2]:

1. continuum flow: $K n \leq 0.001$,

2. slip flow regime: $0.001 \leq K n \leq 0.1$,

3. transition regime: $0.1 \leq K n \leq 10$ and

4. free molecular flow: $K n>10$.

Slip flow regime is investigated in this paper. Navier-Stokes equations are of the order of $K n$, so they are applicable in the slip flow regime together with the first order boundary conditions.

Many studies of rarefied flow in microchannels have been carried out in the past decades. An important analytical and experimental study of gaseous flow in two-dimensional microchannels was carried out in [3]. This study showed that no-slip solution was inadequate in predicting mass flow rate-pressure relationship. Also, the significance of compressibility and rarefied effects was demonstrated.

There are also many analytical studies about gas flows in microtubes in the literature. Analytical studies of [4] and [5] showed the significance of gas compressibility on the pressure distribution but their analysis did not incorporate rarefied behaviour. Analytical solutions for pressure distributions and mass flow rate were developed in [6] for gas flow in microtube at arbitrary Knudsen number. It was shown that the nonlinear pressure distribution was influenced by the gas rarefaction.

Received: May 2014, Accepted: September 2014

Correspondence to: Darko Radenković

Faculty of Mechanical Engineering,

Kraljice Marije 16, 11120 Belgrade 35, Serbia

E-mail: dradenkovic@mas.bg.ac.rs

doi:10.5937/fmet1601010R

(C) Faculty of Mechanical Engineering, Belgrade. All rights reserved
The structure of this paper is as follows. The system of governing equations and boundary conditions are converted into dimensionless form. Then, orders of Reynolds, Mach and Knudsen numbers are analysed. The pressure and velocity are assumed in the form of perturbation series, as in [7], and the solutions for streamwise velocity profile as well as pressure distribution are derived. Then, the mass flow rate of rarefied gas is determined and compared to the experimental results from [8]. Regardless of existing analytical results for rarefied gas flow through microtubes, the solution obtained by the perturbation method is significant. Confirmation of the accuracy of this method by comparing with existing analytical and experimental results enables its applications for more complex axisymmetric flows.

\section{ANALYSIS}

\subsection{Governing equations}

We consider a steady, isothermal, compressible and axisymmetric gas flow in a long microtube. The geometry of a microtube is shown in Fig. 1. The governing equations in cylindrical coordinates are:

- continuity equation

$$
\frac{\partial(\rho u)}{\partial x}=0,
$$

- streamwise momentum equation

$$
\rho u \frac{\partial u}{\partial x}=-\frac{\partial p}{\partial x}+\frac{1}{r} \frac{\partial}{\partial r}\left(\mu r \frac{\partial u}{\partial r}\right)+\frac{\partial}{\partial x}\left(\frac{4}{3} \mu \frac{\partial u}{\partial x}\right),
$$

- radial momentum equation

$$
\frac{\partial p}{\partial r}=\frac{\partial}{\partial r}\left(-\frac{2}{3} \mu \frac{\partial u}{\partial x}\right)+\frac{\partial}{\partial x}\left(\mu \frac{\partial u}{\partial x}\right)
$$

and

- equation of state for an ideal gas

$$
p=\rho R_{\mathrm{g}} T,
$$

where $u$ is the streamwise component of velocity, $p$ is the pressure, $\rho$ is density, $\mu$ is dynamic viscosity and $R_{\mathrm{g}}$ is gas constant. 


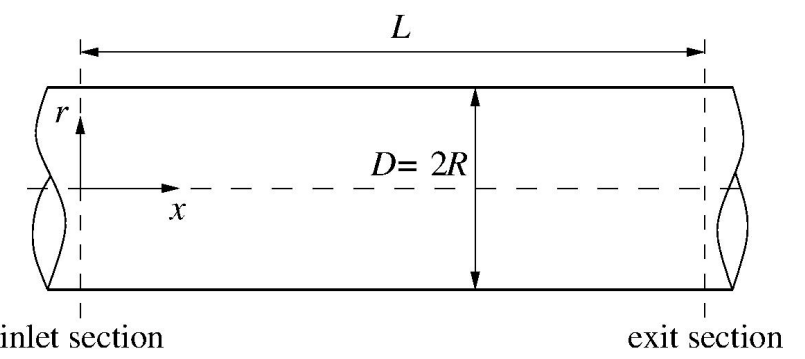

Figure 1. Geometry of a microtube.

The dimensionless variables are defined as:

$\tilde{x}=x / L, \tilde{r}=r / R, \tilde{u}=u / u_{\mathrm{e}}, \tilde{p}=p / p_{\mathrm{e}}, \tilde{\rho}=\rho / \rho_{\mathrm{e}}$, $\tilde{\mu}=\mu / \mu_{\mathrm{e}}$

where $L$ is the microtube length, $R$ is the microtube radius, $u_{\mathrm{e}}$ is the mean streamwise velocity at the microtube exit, $p_{\mathrm{e}}, \rho_{\mathrm{e}}$ and $\mu_{\mathrm{e}}$ are pressure, density and dynamic viscosity at the exit cross section, respectively.

With these dimensionless variables, equations (1) (4) can be recast into the following nondimensional form: - continuity equation

$$
\frac{\partial(\tilde{\rho} \tilde{u})}{\partial \tilde{x}}=0
$$

- streamwise momentum equation

$$
\begin{aligned}
& \kappa M a_{\mathrm{e}}^{2} \tilde{\rho} \tilde{u} \frac{\partial \tilde{u}}{\partial \tilde{x}}=-\frac{\partial \tilde{p}}{\partial \tilde{x}}+\frac{2 \kappa M a_{\mathrm{e}}^{2}}{\varepsilon \operatorname{Re}_{\mathrm{e}}}\left[\frac{1}{\tilde{r}} \frac{\partial}{\partial \tilde{r}}\left(\tilde{\mu} \tilde{r} \frac{\partial \tilde{u}}{\partial \tilde{r}}\right)\right]+ \\
& +2 \varepsilon \frac{\kappa M a_{\mathrm{e}}^{2}}{\operatorname{Re}_{\mathrm{e}}}\left[\frac{\partial}{\partial \tilde{x}}\left(\frac{4}{3} \tilde{\mu} \frac{\partial \tilde{u}}{\partial \tilde{x}}\right)\right],
\end{aligned}
$$

- radial momentum equation and

$$
\begin{aligned}
& \frac{\partial \tilde{p}}{\partial \tilde{r}}=2 \varepsilon \frac{\kappa M a_{\mathrm{e}}^{2}}{\operatorname{Re}_{\mathrm{e}}} \frac{\partial}{\partial \tilde{r}}\left[-\frac{2}{3} \tilde{\mu} \frac{\partial \tilde{u}}{\partial \tilde{x}}\right]+ \\
& +2 \varepsilon \frac{\kappa M a_{\mathrm{e}}^{2}}{\operatorname{Re}_{\mathrm{e}}} \frac{\partial}{\partial \tilde{x}}\left[\tilde{\mu} \frac{\partial \tilde{u}}{\partial \tilde{r}}\right]
\end{aligned},
$$

- equation of state for an ideal gas

$$
\tilde{p}=\tilde{\rho}
$$

where $\kappa$ represents the ratio of specific heats. Mach number $M a_{\mathrm{e}}$ and Reynolds number $R e_{\mathrm{e}}$ are defined in terms of the gas properties at the microtube exit:

$$
M a_{\mathrm{e}}=\frac{u_{\mathrm{e}}}{\sqrt{\kappa p / \rho}} \text { and } R e_{\mathrm{e}}=\frac{\rho_{\mathrm{e}} u_{\mathrm{e}} 2 R}{\mu_{\mathrm{e}}} .
$$

Since the considered problem is isothermal the normalised dynamic viscosity is:

$$
\tilde{\mu}=1 \text {. }
$$

The small parameter $\varepsilon<<1$ is defined as the ratio of the microtube radius to its length $\varepsilon=R / L$.

For the slip gas flow, the velocity at the wall is defined with the first-order Maxwell slip-boundary condition:

$$
\left.\tilde{u}\right|_{\tilde{r}=1}=-\left.2 \frac{2-\sigma_{\mathrm{v}}}{\sigma_{\mathrm{v}}} K n_{\mathrm{e}} \frac{1}{\tilde{p}} \frac{\partial \tilde{u}}{\partial \tilde{r}}\right|_{\tilde{r}=1}
$$

where $\sigma_{\mathrm{v}}$ is the momentum accommodation coefficient, where $\sigma_{\mathrm{v}}=0$ corresponds to specular, while $\sigma_{\mathrm{v}}=1$ to diffusion reflection. Also, $K n_{\mathrm{e}}=\lambda_{\mathrm{e}} / D$ represents Knudsen number at the microtube exit.

\subsection{Additional assumptions}

Gas flow is investigated in this paper at low values of Mach number and it is possible to suppose that the ratio of the square of Mach number to Reynolds number, at the microtube exit, is also of $O(\varepsilon)$ :

$$
2 \frac{\kappa M a_{\mathrm{e}}^{2}}{R e_{\mathrm{e}}}=\gamma \varepsilon,
$$

where coefficient $\gamma=O(1)$. This assumption provides the same order of magnitude of pressure and viscous force in (6). As the considered gas flow is subsonic and slip, it is possible to assume that Mach number and Knudsen number at the microtube exit are proportional to a degree of the small parameter $\varepsilon$ :

$$
\begin{gathered}
\kappa M a_{\mathrm{e}}^{2}=\beta \varepsilon^{m} \\
K n_{\mathrm{e}}=\eta \varepsilon^{n},
\end{gathered}
$$

where coefficients $\beta$ and $\eta$ are both of $O(1)$, and exponents $m$ and $n$ are positive. Knudsen number can be related to the Reynolds number and the Mach number as:

$$
K n=\sqrt{\frac{\pi \kappa}{2}} \frac{M a}{R e} .
$$

Reynolds number at the microtube exit can be expressed from (12) and (13) as:

$$
\operatorname{Re}_{\mathrm{e}}=2 \frac{\beta}{\gamma} \varepsilon^{m-1}
$$

Relation between exponents $m$ and $n$ as well as relation between coefficients $\beta, \eta$ and $\gamma$ can be obtained from (12), (13) and (14) as $2 n+m=2$ and $\beta=\frac{\pi \gamma^{2}}{8 \eta^{2}}$. Since subsonic slip gas flow is considered, parameters $m$ and $n$ must satisfy the following conditions [9], so $m \in(0,2)$ and $n \in(0,1)$.

Based on the equation (16) there are two characteristic flow regimes according to the parameter $m$ :

1. low Reynolds numbers regime, with properties $m \in(1,2)$ and $n \in(0,1 / 2)$ and

2. moderately high Reynolds numbers regime, with properties $m \in(0,1]$ and $n \in[1 / 2,1)$.

Regime of a low Reynolds numbers has been investigated in this paper and parameters $m$ and $n$ must be in the appropriate aforementioned limits. 


\subsection{Non-dimensionalised governing equations and perturbation analysis description}

When assumptions (12), (13) and (14) are inserted in the system of governing equations (5)-(8) and in the boundary condition (11), neglecting the terms of $O\left(\varepsilon^{2}\right)$, equations (5) and (8) retain the same form, while (6), (7) and (11) are simplified as follows:

- streamwise momentum equation

$$
\varepsilon^{\mathrm{m}}\left[\frac{\beta}{\gamma} \tilde{\rho} \tilde{u} \frac{\partial \tilde{u}}{\partial \tilde{x}}\right]=-\frac{1}{\gamma} \frac{\partial \tilde{p}}{\partial \tilde{x}}+\frac{1}{\tilde{r}} \frac{\partial}{\partial \tilde{r}}\left(\tilde{r} \frac{\partial \tilde{u}}{\partial \tilde{r}}\right),
$$

- radial momentum equation

$$
\frac{\partial \tilde{p}}{\partial \tilde{r}}=0
$$

- boundary condition

$$
\left.\tilde{u}\right|_{\tilde{r}=1}=-\varepsilon^{\mathrm{n}}\left[\left.2 \eta \frac{2-\sigma_{\mathrm{v}}}{\sigma_{\mathrm{v}}} \frac{1}{\tilde{p}} \frac{\partial \tilde{u}}{\partial \tilde{r}}\right|_{\tilde{r}=1}\right] .
$$

It follows from(18) that the pressure does not change across microtube cross section, i.e. pressure is a function only on $x$ coordinate $\tilde{p}=\tilde{p}(x)$.

Streamwise velocity $\tilde{u}$ and pressure $\tilde{p}$ are expanded in powers of Knudsen number, according to (14) as

$$
\begin{aligned}
& \tilde{u}=\tilde{u}_{0}+\varepsilon^{n} \tilde{u}_{1}+O\left(\varepsilon^{2 n}\right), \\
& \tilde{p}=\tilde{p}_{0}+\varepsilon^{n} \tilde{p}_{1}+O\left(\varepsilon^{2 n}\right),
\end{aligned}
$$

where the terms with subscripts 0 and 1 are the first and the second approximation of the solution, respectively. Velocity $\tilde{u}$ and pressure $\tilde{p}$, in a form of power series (20) and (21), are substituted in the system of governing equations (5),(8),(17),(18) and boundary condition (19). Terms in equal powers of $\varepsilon$ are collected and the first and the second approximation are derived while the higher approximations are neglected.

\subsection{The first approximation solutions}

The system of governing equations (5),(8),(17),(18) and boundary condition (19) for the first approximation can be written as:

$$
\begin{gathered}
\frac{\partial\left(\tilde{p}_{0} \tilde{u}_{0}\right)}{\partial \tilde{x}}=0, \\
\frac{1}{\gamma} \frac{\mathrm{d} \tilde{p}_{0}}{\mathrm{~d} \tilde{x}}=\frac{1}{\tilde{r}} \frac{\partial}{\partial \tilde{r}}\left(\tilde{r} \frac{\partial \tilde{u}_{0}}{\partial \tilde{r}}\right), \\
\left.\tilde{u}_{0}\right|_{\tilde{r}=1}=0 .
\end{gathered}
$$

From (23) the first approximation for velocity distribution follows:

$$
\tilde{u}_{0}=-\frac{1}{4} \frac{1}{\gamma} \frac{d \tilde{p}_{0}}{\mathrm{~d} \tilde{\mathrm{x}}}\left(1-\tilde{r}^{2}\right) .
$$

From continuity equation (22) a second-order nonlinear ordinary differential equation for the first pressure approximation leads to:

$$
\frac{\partial}{\partial \tilde{x}}\left(\tilde{p}_{0} \tilde{p}_{0}^{\prime}\right)=0
$$

Boundary conditions for the first approximation of pressure are:

$$
\left.\tilde{p}_{0}\right|_{\tilde{x}=0}=\tilde{p}_{0 \mathrm{i}} \text { and }\left.\quad \tilde{p}_{0}\right|_{\tilde{x}=1}=1 .
$$

Analytical solution of (26), with boundary conditions (27) is:

$$
\tilde{p}_{0}=\sqrt{\left(1-\tilde{p}_{0 \mathrm{i}}^{2}\right) \tilde{x}+\tilde{p}_{0 \mathrm{i}}^{2}} \text {. }
$$

When gas flow through microtube is investigated, one of the two following conditions should be given:

1. ratio of inlet to exit pressure $\tilde{p}_{\mathrm{i}}$ or

2. mass flow rate $\tilde{\dot{m}}_{0}$ through microtube.

When the pressure ratio $\tilde{p}_{\mathrm{i}}=\tilde{p}_{0 \mathrm{i}}$ is given, there is no correction of that value in the second approximation. Solutions which contain one (i.e. continuum) and two approximations (gas flow with slip) correspond to different mass flow rates.

In the case when mass flow rate $\tilde{\dot{m}}=\tilde{\dot{m}}_{0}$ is given, there is no correction of that value in the second approximation. The pressure ratio $\tilde{p}_{\mathrm{i}}$ obtained from the first approximation (i.e. continuum) is different from the solution with two approximations (slip flow).

From the first approximation of the dimensionless mass flow rate

$$
\tilde{\dot{m}}_{0}=\int_{0}^{1} \tilde{\rho}_{0} \tilde{u}_{0} 2 \tilde{r} \pi d \tilde{r}
$$

the relation between the first pressure approximation $p_{0 \mathrm{i}}$ and the first approximation of mass flow rate $\tilde{\dot{m}}_{0}$ is obtained solving the differential equation

$$
\tilde{\dot{m}}_{0}=-\frac{1}{8} \frac{1}{\gamma} \pi \tilde{p}_{0} \tilde{p}_{0}^{\prime}
$$

Finally, the relation follows:

$$
\tilde{p}_{0}=\sqrt{1+\frac{16 \gamma \tilde{\dot{m}}_{0}}{\pi}(1-\tilde{x})} .
$$

For $\tilde{x}=0, \tilde{p}_{0}=\tilde{p}_{0 \mathrm{i}}$ from (31) the relation between the ratio of the inlet and exit pressure and the mass flow rate follows:

$$
\tilde{p}_{0 \mathrm{i}}=\sqrt{1+\frac{16 \gamma \tilde{\dot{m}}_{0}}{\pi}} .
$$

From equations (25) and (31) the first approximation for velocity reads:

$$
\tilde{u}_{0}=\frac{2}{\sqrt{1+\frac{16 \gamma \tilde{\dot{m}}_{0}(1-\tilde{x})}{\pi}}} \frac{\tilde{\dot{m}}_{0}}{\pi}\left(1-\tilde{r}^{2}\right) .
$$


Equations for the first approximation of slip gas flow in microtube are indeed the solutions for the gas flow in the continuum conditions.

\subsection{The second approximation solutions}

The second approximation contains only terms of $O\left(\varepsilon^{\mathrm{n}}\right)$. From $m \in(1,2)$ and $n \in(0,1 / 2)$ follow that $O\left(M a^{2}\right)$ is smaller than $O(K n)$. Hence, there is no inertial term in the equation of streamwise momentum as in the first approximation. The second approximation of governing equations (5), (8), (17), (18) and boundary condition (19) at low Reynolds numbers follows:

$$
\begin{aligned}
& \frac{\partial}{\partial \tilde{x}}\left(\tilde{p}_{1} \tilde{u}_{0}+\tilde{p}_{0} \tilde{u}_{1}\right)=0, \\
& \frac{1}{\gamma} \frac{\mathrm{d} \tilde{p}_{1}}{\mathrm{~d} \tilde{x}}=\frac{1}{\tilde{r}} \frac{\partial}{\partial \tilde{r}}\left(\tilde{r} \frac{\partial \tilde{u}_{1}}{\partial \tilde{r}}\right), \\
& \left.\tilde{u}_{1}\right|_{\tilde{r}=1}=-\frac{\alpha}{p_{0}} \frac{\partial u_{0}}{\partial r},
\end{aligned}
$$

where coefficient $\alpha$ is defined as $\alpha=2 \eta \frac{2-\sigma_{\mathrm{v}}}{\sigma_{\mathrm{v}}}$. The velocity distribution in the second approximation is obtained by integration of momentum equation (35) along with the boundary condition (36):

$$
\tilde{u}_{1}=-\frac{1}{4} \frac{1}{\gamma} \frac{d \tilde{p}_{1}}{\mathrm{~d} \tilde{\mathrm{x}}}\left(1-\tilde{r}^{2}\right)-\frac{1}{2} \frac{\alpha \tilde{p}_{0}^{\prime}}{\gamma \tilde{p}_{0}} .
$$

For the known pressure ratio, the second approximation of mass flow rate is not zero. It is straightforward to obtain the following result for the second approximation of mass flow rate from the continuity equation (34):

$$
\tilde{\dot{m}}_{1}=-\frac{1}{8} \frac{1}{\gamma} \pi\left(\tilde{p}_{1} \tilde{p}_{0}\right)^{\prime}-\frac{1}{2} \frac{1}{\gamma} \pi \alpha \tilde{p}_{0}^{\prime} .
$$

Integrating the equation (38) from any cross section to the microtube exit the second approximation for the pressure distribution along microtube follows:

$$
\tilde{p}_{1}=-\frac{8 \gamma}{\pi \tilde{p}_{0}} \tilde{\dot{m}}_{1} \tilde{x}+4 \alpha\left(\frac{\tilde{p}_{i}}{\tilde{p}_{0}}-1\right) .
$$

For the exit cross section, $\tilde{x}=1, \quad \tilde{p}_{1}=0$ and $\tilde{p}_{0}=1$, the relation between the ratio of the inlet and exit pressure and the second approximation of mass flow rate leads from the equation (39):

$$
\tilde{\dot{m}}_{1}=\frac{\pi \alpha}{2 \gamma}\left(\tilde{p}_{i}-1\right)
$$

Now, the solution for the mass flow rate in the case of slip gas flow is:

$$
\tilde{\dot{m}}=\tilde{\dot{m}}_{0}+\frac{K n_{\mathrm{e}}}{\eta} \tilde{\dot{m}}_{1}
$$

Since the second approximation of the mass flow rate (40) is positive, it follows from (41) that for the same inlet-exit pressure ratio, the mass flow rate in a case of a rarefied gas $\tilde{\dot{m}}$ is greater than the mass flow rate in a continuum conditions $\tilde{\dot{m}}_{0}$. Ratio of these two mass flow rates can be easily derived from (32), (40) and (41):

$$
\frac{\tilde{\dot{m}}}{\tilde{\dot{m}}_{0}}=1+16 K n_{\mathrm{e}} \frac{2-\sigma_{\mathrm{v}}}{\sigma_{\mathrm{v}}} \frac{1}{\tilde{p}_{\mathrm{i}}+1} .
$$

If the whole value of the mass flow rate is contained in the first approximation i.e. $\tilde{\dot{m}}=\tilde{\dot{m}}_{0}, \quad \tilde{\dot{m}}_{1}=0$, then from equation (38) the differential equation for the pressure second approximation follows:

$$
\frac{\partial}{\partial \tilde{x}}\left(\tilde{p}_{1} \tilde{p}_{0}\right)+4 \alpha \frac{\partial \tilde{p}_{0}}{\partial \tilde{x}}=0 .
$$

Integrating this equation from any cross section to the microtube exit, using appropriate boundary conditions:

$$
\left.\tilde{p}_{0}\right|_{\tilde{x}=1}=1 \text { and }\left.\tilde{p}_{1}\right|_{\tilde{x}=1}=0,
$$

the second approximation of pressure reads:

$$
\tilde{p}_{1}=4 \alpha\left(\frac{1}{\tilde{p}_{0}}-1\right) \text {. }
$$

In this case, the second pressure approximation has negative values along microtube, except in the exit section, where it is zero. Hence, pressure values along a microtube in the case of rarefied gas are lower compared to continuum flow, for the same mass flow rate.

\subsection{Final solutions for velocity and pressure}

Finally, the complete analytical solution for isothermal rarefied gas flow in a microtube at small Reynolds numbers will be presented.

If mass flow rate is known as condition, i.e. $\tilde{\dot{m}}=\tilde{\dot{m}}_{0}$ then analytical solution for velocity and pressure distribution, with respect to (20), (21), (31), (33), (37) and (45) is:

$$
\tilde{u}=\frac{2}{\sqrt{1+\frac{16 \gamma \tilde{\dot{m}}(1-\tilde{x})}{\pi}}} \frac{\tilde{\dot{m}}}{\pi}\left(1-\tilde{r}^{2}\right)+\frac{4 \frac{K n_{\mathrm{e}}}{\eta} \alpha \tilde{\dot{m}}}{\pi\left(1+\frac{16 \gamma \tilde{\dot{m}}(1-\tilde{x}))}{\pi}\right)}
$$

$$
\left[\frac{2}{\sqrt{\left(1+\frac{16 \gamma \tilde{\dot{m}}(1-\tilde{x})}{\pi}\right)}}\left(\tilde{r}^{2}-1\right)+1\right]
$$

$$
\begin{aligned}
& \tilde{p}=\sqrt{1+\frac{16 \gamma \tilde{\dot{m}}}{\pi}(1-\tilde{x})}+ \\
& +4 \frac{K n_{\mathrm{e}}}{\eta} \alpha\left(\frac{1}{\sqrt{1+\frac{16 \gamma \tilde{\dot{m}}}{\pi}(1-\tilde{x})}}-1\right)
\end{aligned}
$$


If the ratio of the inlet and exit microtube pressure $\tilde{p}_{0 \mathrm{i}}=\tilde{p}_{\mathrm{i}}$ is given as condition, then solution for velocity and pressure distribution, with respect to (22), (23), (27), (30) and (39) is:

$$
\begin{gathered}
\tilde{u}=\frac{\tilde{p}_{\mathrm{i}}^{2}-1}{8 \gamma} \frac{1}{\sqrt{\left(1-\tilde{p}_{\mathrm{i}}^{2}\right) x+\tilde{p}_{\mathrm{i}}^{2}}}\left(1-\tilde{r}^{2}\right)+ \\
+\frac{K n_{\mathrm{e}}}{\eta}\left[-\frac{1}{2} \frac{\alpha}{\gamma} \frac{\left(\tilde{p}_{\mathrm{i}}-1\right)^{2}\left(\tilde{p}_{\mathrm{i}}(\tilde{x}-1)+\tilde{x}\right)}{\left(\tilde{x}-\tilde{p}_{\mathrm{i}}^{2}(\tilde{x}-1)\right)^{3 / 2}}\left(1-\tilde{r}^{2}\right)-\right. \\
\left.-\frac{1}{4} \frac{\alpha}{\gamma} \frac{1-\tilde{p}_{\mathrm{i}}^{2}}{\left(1-\tilde{p}_{\mathrm{i}}^{2}\right) x+\tilde{p}_{\mathrm{i}}^{2}}\right] \\
\tilde{p}=\sqrt{\left(1-\tilde{p}_{\mathrm{i}}^{2}\right) \tilde{x}+\tilde{p}_{\mathrm{i}}^{2}}+ \\
4 \alpha \frac{K n_{\mathrm{e}}}{\eta}\left[\frac{\tilde{p}_{i}}{\tilde{p}_{0}}(1-\tilde{x})+\left(\frac{\tilde{x}}{\tilde{p}_{0}}-1\right)\right]
\end{gathered}
$$

Substituting the boundary condition $\tilde{x}=0$ and $\tilde{p}=\tilde{p}_{\mathrm{i}}$ in the equation (47) the relation between mass flow rate and the ratio of the inlet and exit microtube pressure $\tilde{p}_{\mathrm{i}}$ is obtained as:

$$
\tilde{\dot{m}}=\frac{-b+\sqrt{b^{2}-4 c}}{2},
$$

where the coefficients are defined as

$$
b=\frac{\pi^{2}}{256 \gamma^{2}}\left[\frac{32 \gamma}{\pi}\left(1+4 \frac{K n_{\mathrm{e}}}{\eta} \alpha\right)-\frac{16 \gamma}{\pi}\left(\tilde{p}_{i}+4 \frac{K n_{\mathrm{e}}}{\eta} \alpha\right)^{2}\right]
$$

and

$$
c=\frac{\pi^{2}}{256 \gamma^{2}}\left[\left(1+4 \frac{K n_{\mathrm{e}}}{\eta} \alpha\right)^{2}-\left(\tilde{p}_{i}+4 \frac{K n_{\mathrm{e}}}{\eta} \alpha\right)^{2}\right] .
$$

Hence, if the ratio of the inlet and exit microtube pressure $\tilde{p}_{\mathrm{i}}$ is given, the mass flow rate follows from (50), and then the velocity and pressure distribution follow from (46) and (47), respectively.

\section{RESULTS AND DISSCUSION}

\subsection{Pressure distribution}

The pressure distributions $\tilde{p}$ are shown in Fig. 2. for a long microtube, for example, for the pressure ratio $\tilde{p}_{\mathrm{i}}=3$. The pressure distributions for three cases are compared: the continuum incompressible flow, no-slip compressible flow and slip compressible flow with $K n_{\mathrm{e}}=0.1$. The pressure distribution for continuum incompressible flow is linear. Including compressibility into consideration the predicted pressure distribution becomes nonlinear, and the pressure is higher along the microtube. As opposed to the effect of compressibility, the rarefaction effect reduces the pressure nonlinearity and the pressure values along the microtube [3], [9].

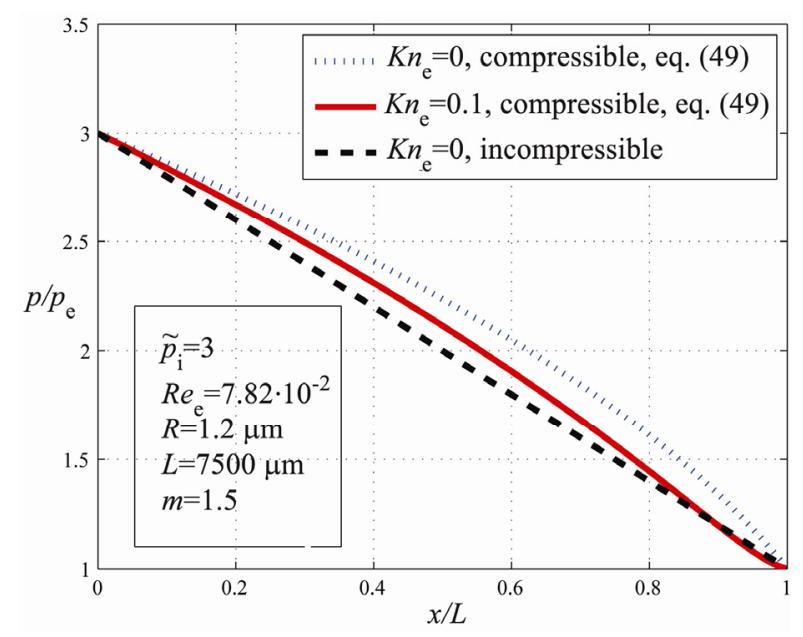

Figure 2. The pressure distribution in a long microtube when the pressure ratio is given, equation (49).

In Figure 3 the pressure distribution $\tilde{p}$ along microtube with slip $\left(K n_{\mathrm{e}}=0.1\right)$ and no-slip, for the same mass flow rate are presented. The rarefaction effect leads to lower pressure in microtube.

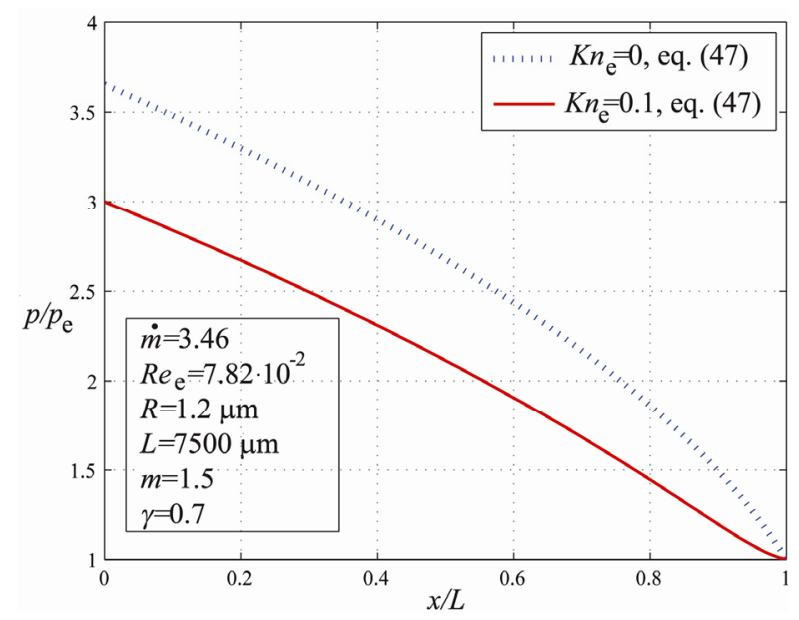

Figure 3. The pressure distribution in a long microtube when the mass flow rate is given, equation (47).

\subsection{Velocity distributions}

Shown in Figures 4 and 5 are the streamwise velocity distributions in long microtubes, for both slip gas flow $\left(K n_{\mathrm{e}}=0.1\right)$ and continuum gas flow $\left(K n_{\mathrm{e}}=0\right)$. These velocity distributions are parabolic and they gradually change along the microtube. In the case of the rarefied gas flow, the slip velocity at the wall increases toward the microtube exit. To enforce mass continuity, fluid will migrate from the channel centreline toward the wall [3].

The influence of the gas rarefaction on the mass flow rate is seen in Fig. 6. The solid line represents the solution (42), i.e. mass flow rate ratio for the slip and continuum gas flow, for different inlet-exit pressure ratios $\tilde{p}_{i}$. Increase of the mass flow rate for rarefied gas flow compared to the continuum mass flow rate is higher for the lower pressure inlet-exit ratios.

Figure 6 also shows the comparison between presented analytical results and experimental data obtained by Yang and Garimella [8]. The analytical solution agrees very well with experimental data. 


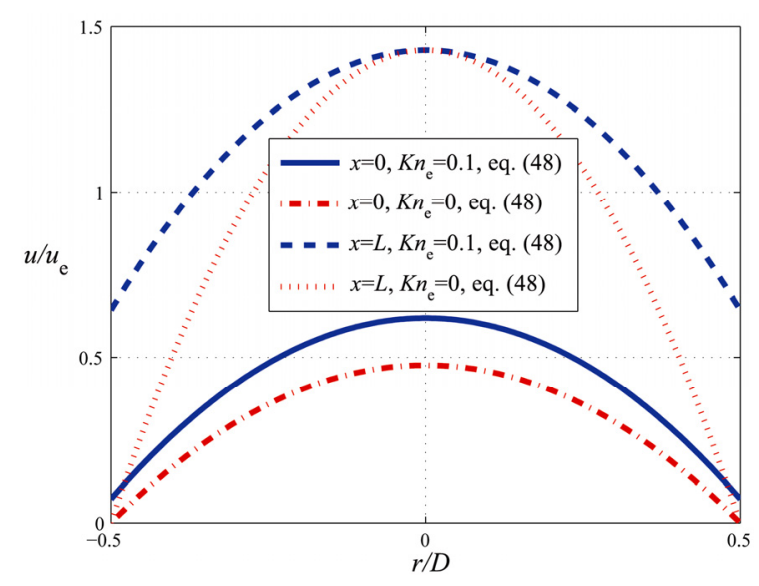

Figure 4. The streamwise velocity distributions in a long microtube at inlet and outlet cross-section.

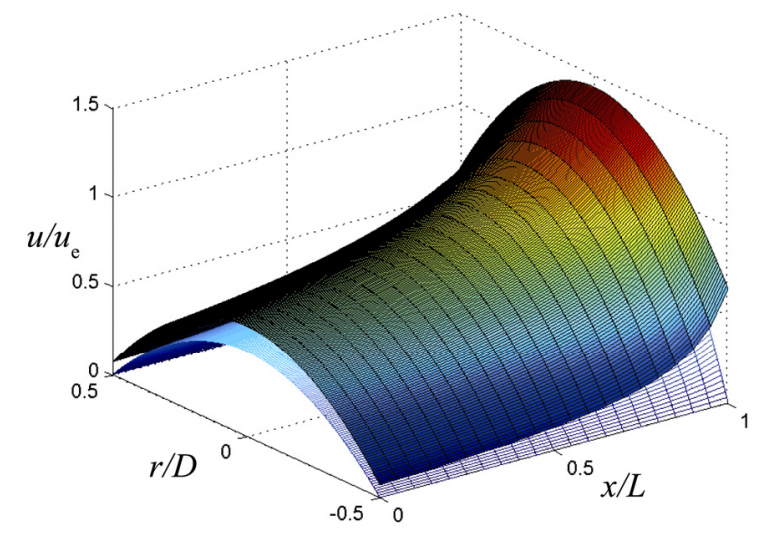

Figure 5. The streamwise velocity distributions in a long microtube for $\tilde{p}_{i}=3$. The upper surface represents the results for a flow with $K n_{e}=0.1$; the lower surface represents the results for flow with no rarefaction.

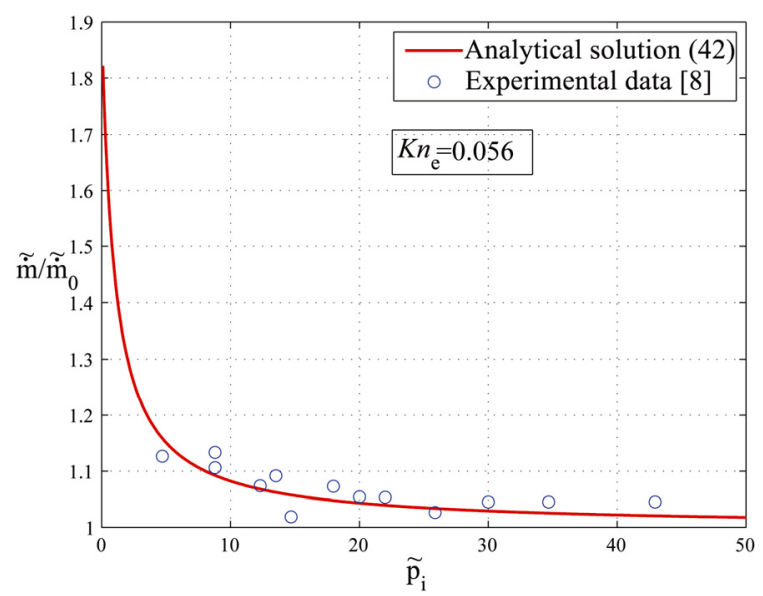

Figure 6. The solid line represents the mass flow rate ratio for the slip and continuum flow, for different inlet and exit pressures ratios.

\section{CONCLUSION}

We have performed perturbation expansion analysis of Navier-Stokes equations with the first-order slip condition, in the regime of a low Reynolds number. It has been demonstrated that compressibility tends to make pressure distribution nonlinear and gas rarefaction tends to diminish that effect. Analytical solutions for velocity and pressure distributions have been derived.

It has been shown that slip velocity increases toward the microtube exit. Also, the analytical solution for the mass flow rate ratio of rarefied and continuum gas flow has been obtained. This solution agrees well with the experimental results obtained by Yang and Garimella [8]. This confirms the accuracy of presented method, which provides the opportunity to obtain more complex solutions that include inertia, non-isothermal and flows in variable microtube cross sections.

\section{ACKNOWLEDGMENT}

This work is supported by the Ministry of Education and Science of the Republic of Serbia, project TR 35046, which we gratefully acknowledge.

\section{REFERENCES}

[1] Gad-el-Hak, M.: The MEMS Handbook, CRC Press, Boca Raton, 2002.

[2] Beskok, A., Karniadakis, G.E.: A model for flows in channels, pipes and ducts at micro and nano scales, J. Microscale Thermophys. Eng., Vol. 3., No. 1, pp. 43-77, 1999.

[3] Arkilic, E.B., Schmidt, M.A. and Breuer, K.S.: Gaseous slip flow in long microchannels, J. Microelectromech. Syst., Vol. 6., No. 2, pp. 167-178, 1997.

[4] Prud'homme, R.K., Champman T.W. and Bowen, J.R.: Laminar compressible flow in a tube, Appl. Sci. Res., Vol. 43, pp. 67-74, 1986.

[5] Van den Berg, H., Seldam, C. and Gulik, P., Compressible laminar flow in a capillary, J. Fluid Mech., Vol. 246, pp. 1-20, 1993.

[6] Weng, C.I., Li, W.L. and Hwang, C.C.: Gaseous flow in microtubes at arbitrary Knudsen numbers, Nanotechnology, Vol. 10, No. 4, pp. 373-379, 1999.

[7] Milićev, S. S., Stevanović, D. N.: “A non-isothermal Couette slip gas flow", Science China Physics, Mechanics and Astronomy, Vol. 56, No. 9, September 2013, pp. 1782-1797.

[8] Yang, Z. and Garimella, S.: Rarefied gas flow in microtubes at different inlet-outlet pressure ratios, Phys. Fluids, Vol. 21, 052005 , pp. 2009.

[9] Milićev, S.: Non-isothermal flow of rarefied gas in microchannels, $\mathrm{PhD}$ thesis, University of Belgrade, Faculty of Mechanical engineering, Belgrade, 2011.

\section{СТРУЈАҢЕ РАЗРЕЪЕНОГ ГАСА У МИКРОЦЕВИМА ПРИ МАЛИМ РЕЈНОЛДСОВИМ БРОЈЕВИМА}

\section{Дарко Р. Раденковић, Снежана С. Милићев, Невена Д. Стевановић}

У раду се проучава осносиметрично, изотермско, стишљиво струјање гаса са клизањем, при малим вредностима Рејнолдсовог броја. Проблем је решен применом једначине континуитета и Навије-Стоксових једначина, заједно са Максвеловим граничним условом првог реда. Аналитички резултати су добијени применом пертурбационе методе. Добијена решења се добро слажу са познатим експерименталним резултатима других аутора. 